\title{
HISTORIA DE LA CONQUISTA, PÉRDIDA Y RESTAURACIÓN DE LA NUEVA MÉXICO: ESCRIBIENDO LA HISTORIA OFICIAL DE LA FRONTERA NORTE DEL IMPERIO ESPAÑOL DE ACUERDO CON JUAN DE VILLAGUTIERRE Y SOTOMAYOR, RELATOR DEL CONSEJO DE INDIAS, 1706
}

\author{
HISTORIA DE LA CONQUISTA, PÉRDIDA Y RESTAURACIÓN \\ DE LA NUEVA MÉXICO: WRITING THE OFFICIAL HISTORY \\ OF THE NORTHERN FRONTIER OF THE SPANISH EMPIRE ACCORDING \\ TO JUAN DE VILLAGUTIERRE Y SOTOMAYOR, RELATOR \\ OF THE COUNCIL OF THE INDIES, 1706
}

\section{Teri Erandeni Arias Ortiz}

Arbeitskreis Stadtgeschichte e.V./Gedenk- und Dokumentationsstätte KZ Drütte, Alemania teriariasortiz@gmail.com

\section{Argelia Segovia Liga}

Missouri State University, Missouri, EUA

argeliasegovialiga@gmail.com

\begin{abstract}
Resumen
El siguiente trabajo tiene como objetivos revisar brevemente la vida de Juan de Villagutierre y Sotomayor, relator del Consejo de Indias a finales del siglo XVII e inicios del XVIII, y explorar de forma general el contenido de una de sus obras dedicada a la historia de la entonces provincia de Nuevo México. Este manuscrito, muy poco conocido, es único en su género por varias razones; una de ellas es el hecho de que la obra puede considerarse como una revisión general del territorio y su gente, ya que incluye su historia indígena, hispánica y colonial. La otra es que el discurso de la obra ofrece una interpretación secular de la historia, por lo que los personajes principales que aparecen en la narración pertenecen a la esfera civil de la Corona española, y no a la religiosa.
\end{abstract}

Palabras clave: Nuevo México, Juan de Villagutierre Sotomayor, exploraciones españolas, rebeliones indígenas, indígenas del norte, Santa Fe.

\begin{abstract}
The following essay has the purpose of both briefly reviewing the life of Juan de Villagutierre y Sotomayor, relator of the Council of the Indies at the end of the 17th century and the beginning of the 18th century, and to explore the content of one of his lesser known works, which he dedicated to the history of the then Province of New Mexico. This last manuscript is unique for several reasons; one of them is the fact that this work can be considered as one of the first general revisions of the history of the New Mexico territory and its inhabitants, since this manuscript includes details on the indigenous past of the province, and focuses generally on its Pre-Hispanic, conquest and colonial history. The other reason that makes this work unique is that the discourse of the work offers for the first time a secular interpretation of the history of New Mexico, which explains the reason why the author focused his narrative
\end{abstract}


on the main characters that belong more to the civil sphere of the Spanish crown, rather than focusing his narration on those protagonists who belonged to the religious sphere.

Keywords: New Mexico, Juan de Villagutierre Sotomayor, Spanish explorations, indigenous rebellions, indigenous peoples from the north, Santa Fe.

Información del artículo

Recibido: 21 de septiembre de 2018.

Aceptado: 1 de febrero de 2019.

DOI: $10.22201 /$ iih.24486922e.2019.60.67214

\section{Introducción ${ }^{1}$}

La historiografía acerca de los procesos de conquista y colonización del continente americano y sus pobladores ofrece un incontable número de trabajos que permiten el estudio de la historia de lo que los europeos denominaron "el Nuevo Mundo". A partir del siglo xvi diversos actores históricos escribieron obras con el objetivo de dejar testimonio de las exploraciones, explicar la relación que existía entre los habitantes de España y la gente de los reinos de Indias, así como justificar la presencia española en estos territorios. Muchos de esos trabajos son testimonios autobiográficos de aquellos quienes viajaron allende el mar océano; desde la península ibérica otros autores crearon crónicas oficiales para sosegar el rigor administrativo y las demandas de la Corona de Castilla, y justificar la expansión imperial de España en el Nuevo Mundo. ${ }^{2}$ Las crónicas referidas poseen sus propias características, las cuales obedecen a la diversidad de los autores y a las regiones de América acerca de las cuales escribieron sus obras.

Dada la variedad de obras acerca de la exploración, conquista y colonización de los territorios americanos, y en un intento por mejorar la sistematización de la creación de conocimiento acerca de las tierras conquistadas, en las Ordenanzas de 1571 del Real y Supremo Consejo de las Indias la Corona española instauró la posición de "cronista y cosmógrafo mayor

${ }^{1}$ Queremos expresar nuestro agradecimiento al doctor Gary Van Valen, de la Universidad del Oeste de Georgia, en los Estados Unidos, por su ayuda en la primera fase de esta investigación. Del mismo modo, agradecemos a Pablo Andrés Escapa, bibliotecario de la Real Biblioteca del Palacio Real de Madrid, España, por facilitarnos información adicional acerca del manuscrito de la historia de Nuevo México de Villagutierre Sotomayor.

${ }^{2}$ Cuesta Domingo (2007, pp. 115-150). 
de las tierras y reinos de las Indias, islas y tierra firma del océano”. Esta posición seguía los lineamientos del Real y Supremo Consejo de Indias, órgano rector de la legislación y regulación para la colonización del Nuevo Mundo español. ${ }^{3}$ Aunque de acuerdo con el protocolo la tarea de escribir la historia oficial de los territorios americanos estaba reservada para los "cronistas reales", esto no impidió que otros individuos u oficiales reales escribieran sus testimonios y otros documentos concernientes a las Indias Occidentales. A lo largo del periodo colonial, la producción de crónicas, relatos, memorias y relaciones históricas encontraron una prolífica actividad entre clérigos, miembros de las cortes y colonizadores.

Entre aquellos que escribieron historias acerca de los territorios americanos, se encuentra el abogado Juan Villagutierre Sotomayor ${ }^{4}\left(\dot{\imath}^{2}-\dot{i} 1710\right.$ ?), relator del Consejo de Indias, quien a finales del siglo XvII escribió un manuscrito acerca de la frontera entre la Nueva España y la Audiencia de Guatemala. Esta es su obra más conocida y recibió el título de Historia de la conquista de la provincia del Itza, reduccion, y progressos de la de el Lacandon, y otras naciones de indios bárbaros de la mediación de el Reyno de Guatemala a las provincias de Yucatan en la America Septentrional, publicada por primera vez en 1701. Pocos años después Villagutierre también concluyó otro amplio manuscrito, pero menos conocido: Historia de la conquista, perdida y restaurazion de el Reyno y Provinzias de la Nueba México en la América Septentrional. Contrariamente a la suerte de su primera obra, esta última nunca llegó a publicarse, razón por la cual ha permanecido casi en el desconocimiento y con una mínima difusión en el mundo académico. De este manuscrito existen dos copias, una de ellas resguardada en la Real Biblioteca del Palacio Real de España y otra en la Biblioteca Nacional de España (en adelante, BNE), ambas en Madrid, España.

La contribución histórica de esta obra acerca de Nuevo México reside en la invaluable información que brinda sobre la geografía del territorio, la historia de sus habitantes originales y las exploraciones españolas llevadas a cabo a lo largo de dicha región. Adicionalmente esta historia presenta un modelo historiográfico que evidencia la interpretación oficial acerca de las Américas desde la perspectiva del Estado, creada desde la burocracia de la administración oficial del imperio español. Esta característica brinda a los

${ }^{3}$ Cuesta Domingo (2007, p. 119).

${ }^{4}$ En varias fuentes también aparece como Villagutierre y Sotomayor o Soto-Mayor, o Juan de Villagutierre y Sotomayor. 
interesados en el tema la posibilidad de revisar este manuscrito no sólo como un texto narrativo, sino también como resultado de los intentos administrativos por parte de la Casa de los Habsburgo para adquirir información útil acerca de los territorios que su imperio tenía subyugados. ${ }^{5}$

Sin embargo, cabe resaltar que, a pesar de la notoria cantidad de fuentes que el relator consultó para componer este manuscrito, similar a su previa historia de la conquista del Itzá, Villagutierre no dio crédito a sus fuentes ni hizo referencia a ellas. No obstante, como documento histórico, esta obra acerca de la provincia de Nuevo México ofrece interesantes paradigmas para desarrollar futuras investigaciones, ya sea analizando las fuentes que el relator consultó para formar este manuscrito, o para conocer las motivaciones que llevaron al relator a escribir dicho texto. Además, esta obra proporciona una visión interna que revela los temores, las amenazas y las numerosas crisis que la última Casa de los Habsburgo enfrentó durante el tiempo en que Villagutierre completaba el mencionado escrito. ${ }^{6}$

Así, el siguiente trabajo tiene como objetivo explorar de manera general el contenido de la Historia de la conquista, perdida y restaurazion..., ofrecer algunas hipótesis acerca de las probables motivaciones que tuvo Villagutierre Sotomayor para escribir esta obra, así como revisar el contexto histórico de España al momento que el autor concluyó el manuscrito.

Juan Villagutierre (y) Sotomayor, relator del Consejo de Indias

A pesar de la escasez de fuentes acerca de la vida de Juan de Villagutierre, sabemos que fue natural de Valladolid: "hijo de D. Pedro de Villagutierre Sotomayor y de D[oñ]a Ana María Pereira de Castro, contrajo matrimonio el 4 de julio de 1708 con D[oñ]a Baltasara de Tapia, natural de Madrid, hija de D[on] José de Tapia y Quiroga, y de D[oñ]a María de la Fuente".7

Algunas referencias afirman que Villagutierre trabajó como abogado de la Real Chancillería de Valladolid, ${ }^{8}$ y que ocupó la posición de relator en el Consejo de Indias desde el 10 de marzo de 1696 hasta principios de $1709 .{ }^{9}$

${ }^{5}$ Greußlich (2012, p. 6).

${ }^{6}$ Para más información acerca de la importancia que la frontera norte tenía para el imperio español durante la segunda mitad del siglo xvıII, véase la obra de Meza (2009).

${ }^{7}$ Matías Fernández (1995, p. 577).

${ }^{8}$ Schäfer (2003, p. 360).

${ }^{9}$ Lárraga (1999, p. 3 ). 
De igual forma existen referencias que apuntan que Villagutierre tuvo una hija, ${ }^{10}$ y que él habría muerto entre 1709 y 1710 sin nunca haber visitado las Américas.

El oficio de relator que ocupaba Villagutierre Sotomayor dependía de nombramiento real, y a pesar de no existir especificaciones acerca de las credenciales de los aspirantes a esta posición, la mayoría de ellos ostentaron el título de licenciados, aunque también hubo bachilleres y algunos doctores; Villagutierre ostentaba el título de licenciado. ${ }^{11}$ El tiempo de duración del cargo podía ser indefinido y otorgado por sanción real, y sólo interrumpida por la muerte del relator en turno. El oficio de relator era una actividad remunerada, con un sueldo establecido por la real hacienda, el cual se complementaba con los derechos fijados por arancel. ${ }^{12}$ Considerando que Villagutierre inicialmente laboró como relator en la Chancillería de Valladolid, entonces concluimos que éste ostentó la calificación de licenciado en Derecho, pues para corroborar los conocimientos del aspirante en la chancillería éste tenía que aprobar un examen ante el presidente y los oidores de la Audiencia. ${ }^{13}$

De acuerdo con los lineamientos estipulados en la Recopilación de Leyes de los reynos de las Indias de 1680, en el libro segundo, título noveno, en su oficio de relator Juan Villagutierre debía preparar extractos, proveer referencias a casos legales, reunir testimonios, memorias y otros documentos necesarios para completar los expedientes, así como escribir las minutas, resúmenes y copias de los decretos, y decisiones de la corte. ${ }^{14}$ Además, según las propias Leyes de Indias los relatores debían guardar las "Leyes de Castilla", ${ }^{15}$ mantener el secreto del Consejo, no compartir documentos con otros burócratas, hacer los memoriales por su mano, escribir los decretos y pasarlos al consejero en turno. ${ }^{16}$ El relator también tenía la labor de asistir personalmente a las reuniones del Consejo y tomar notas acerca de lo deliberado en cada sesión.

${ }^{10}$ Quien a su vez se casó con don Manuel de Arredondo, relator en el Consejo de Indias. Véase Lárraga (1999, pp. 5-6).

${ }^{11}$ Bermúdez Aznar (2008, p. 430).

12 Bermúdez Aznar (2008, p. 431).

13 Bermúdez Aznar (2008, p. 434).

${ }^{14}$ Dougnac Rodríguez (1994, p. 149).

${ }^{15}$ Soler (1529, f. iiii).

${ }^{16}$ Recopilación de leyes (1841, p. 195-197). 
Con base en diversas fuentes podemos corroborar que Villagutierre y Sotomayor escribió varios documentos oficiales propios de las reglas y protocolos bajo los cuales se regía su labor. Algunos de los manuscritos de su autoría se encuentran actualmente resguardados en diversos archivos españoles. El Archivo General de Indias (en adelante, AGI) resguarda por lo menos dos documentos: uno de ellos es el "Oficio de Manuel de Aperregui [secretario del Consejo], a Juan de Villagutierre, [relator del Consejo de Indias], remitiéndole carta del arzobispo de México, virrey interino de Nueva España. Madrid, 16 de mayo de 1702"; ${ }^{17}$ y el segundo clasificado como "1705 Juan de Villagutierre, relator de este Consejo, con Alonso de Acevedo, procurador, sobre paga de los derechos de un pleito determinado en 1705 ". ${ }^{18}$ Según los documentos, la muerte del relator Villagutierre ocurrió entre 1709 y 1710 pues existe una petición del 18 de agosto de 1710 en la que Juan de Diego y Vallejo pidió licencia para ocupar la posición del difunto Villagutierre, lo que podría sugerir que la fecha de deceso del relator Villagutierre fue en 1710 o un año anterior a éste. ${ }^{19}$ Esta fecha coincide con el cese de producción documental del relator Villagutierre.

Si bien la labor de relator estaba claramente estipulada en los documentos correspondientes, esto no explica las razones por las cuales el relator Villagutierre escribió el manuscrito acerca de la historia de la conquista española del norte de las Américas. Es así que surge la pregunta obligada e indagar acerca de los motivos que Villagutierre tuvo para escribir esta obra acerca de la frontera norte de la Nueva España.

De acuerdo con la documentación pertinente, sabemos que en muchos casos la posición de relator era utilizada como un punto para ascender en el escalafón de promociones laborales dentro de la burocracia española. El académico Agustín Bermúdez menciona dos ejemplos dignos de citarse: "en cuanto trampolín para acceder a otras plazas indianas cabe citar el caso del Licenciado Rabanal, relator del Consejo, quien fue nombrado fiscal de la Audiencia de México, y también el del Licenciado Duarte de Acuña nombrado corregidor de Mérida [...]" ${ }^{20}$

${ }^{17}$ Oficio de Manuel de Aperregui a Juan de Villagutierre, remitiéndole carta del arzobispo de México, virrey interino de Nueva España, Madrid, 16 de mayo de 1702, Archivo General de Indias (en adelante, AGI), Filipinas, 204, N. 1, f. 1r.

18 Juan de Villagutierre, relator de este Consejo, con Alonso de Acevedo, procurador, sobre paga de los derechos de un pleito, 1705, AGI, Escribanía 1052 A.

${ }^{19}$ Lárraga (1999, p. 5).

${ }^{20}$ Bermúdez Aznar (2008, p. 444). 
En el caso de Villagutierre Sotomayor, éste aparentemente escribió la historia de la conquista del Petén Itzá por comisión directa del Consejo de Indias para apoyar al conquistador don Martín de Ursúa y Arizmendi, quien se encontraba en una posición crítica después de haber concluido la pacificación del Petén Itzá. A Ursúa se le acusaba de abuso de poder, maltrato de indígenas y gasto innecesario de los fondos coloniales para concretar el Camino Real de Tierra Adentro, el cual comunicaría a Yucatán y Guatemala. ${ }^{21}$ Debido al apoyo que el Consejo de Indias y el rey de España daban a Ursúa, los anteriores solicitaron a Villagutierre que escribiera la historia de la conquista del Itzá, para lo cual el mismo consejo puso a disposición del relator un importante número de documentos referentes a las entradas de conquista y pacificación del Petén, así como documentos de la autoría del mismo Ursúa. Aunado a las negociaciones políticas pertinentes, el manuscrito resultó en el éxito de Ursúa contra sus enemigos.

Contrariamente a esta explicación que esclarece los motivos que Villagutierre tuvo para escribir la historia de la conquista del Itzá, a la fecha no existen estudios que exploren los motivos que Villagutierre Sotomayor tuvo para escribir la historia de la conquista de Nuevo México. Es por eso que aventuramos dos hipótesis. En la primera de ellas sostenemos que Villagutierre posiblemente tuvo intenciones de adquirir una posición más alta dentro de la esfera burocrática española al terminar esta obra; la segunda, que es la que sostenemos en este breve ensayo, es que el manuscrito responde a otra solicitud hecha directamente por el Consejo de Indias, o algún miembro de la alta burocracia real, para dejar testimonio del proceso de transición que la Casa de los Habsburgo experimentaba en ese tiempo y que terminaría con la instalación de los Borbones en el trono español.

Siguiendo con las comparaciones, la obra acerca de la conquista del Itzá se publicó, mientras que la obra acerca de Nuevo México permanece inédita, situación que genera la pregunta de saber el porqué una obra de Villagutierre se publicó, mientras que la otra no. Al respecto, Giovanni Stiffoni menciona a manera de hipótesis la posibilidad de que Villagutierre haya publicado su obra acerca del Itzá para impedir que se imprimiera la obra Recordación florida (1690), de Francisco Antonio Fuentes de Guzmán. ${ }^{22}$ Así, además de considerar las posibles rencillas que existían entre los miembros del Consejo de Indias que pudieran haber obstaculizado la publicación

${ }^{21}$ Jones (1998, p. XXII).

${ }^{22}$ Stiffoni (1984, p. 139). 
de la obra de Villagutierre, también defendemos la hipótesis que sostiene que el manuscrito acerca de Nuevo México no se publicó porque el autor lo concluyó en un momento de coyuntura política poco favorable para los Habsburgo, aunado a la subsecuente muerte de Villagutierre.

Juan Villagutierre Sotomayor y la mención de sus obras

La obra del relator Villagutierre acerca de la conquista del Itzá es tan representativa que existen numerosas referencias acerca de este manuscrito. A pesar de que su obra acerca de la historia de Nuevo México no fue publicada, ha merecido la mención de diversos autores. La primera de ellas se encuentra en el Ensayo cronológico para la historia general de la Florida, de Andrés González de Barcia, quien bajo el pseudónimo de Gabriel Cárdenas y Cano ${ }^{23}$ lo publicó en $1723 .{ }^{24}$ González de Barcia enumeró en su estudio una serie de trabajos que contribuyeron al conocimiento de las regiones de América, y entre ellas se encuentran las obras de Villagutierre. Al respecto, Cárdenas y Cano incluyó lo siguiente: "Historia del Nuevo Mejico, escrita por el lic[enciado] Don Juan de Villagutierre, relator del Consejo de Indias, en folio, que el original está en la librería del señor don Gerónimo Pardo, del Consejo de Castilla, y la Historia de la Conquista de la Provincia del Ytza [...]”. 25

En 1906 Manuel Serrano y Sáenz, en su obra Relación de los naufragios y comentarios de Álvar Núñez Cabeza de Vaca, mencionó implícitamente la obra de Villagutierre acerca de Nuevo México en los siguientes términos: "Tal es la verídica pintura que de los indios del Nuevo México, bastante afines a los de las Floridas, nos dejó D[on] Juan de Villagutierre y Sotomayor [...]". ${ }^{26}$ Consecuentemente, en 1985 Jesús María García Añoveros, en su estudio introductorio para la edición de la Historia de la conquista del Itzá ${ }^{27}$ del propio Villagutierre y Sotomayor, propuso que el relator Villagutierre escribió además otros textos referentes a la Nueva Orbe. Entre la lista de los supuestos manuscritos de Villagutierre, García incluyó los siguientes:

\footnotetext{
${ }^{23}$ López de Azcona et al. (1992, p. 462). También véase Alamán (1853, p. 62).

${ }^{24}$ Cárdenas y Cano (1723).

${ }^{25}$ Cárdenas y Cano (1829, p. 44).

${ }^{26}$ Núñez Caveza de Vaca (1906, p. XIX).

${ }^{27}$ Villagutierre Sotomayor (1985, p. 7).
} 
1) Relación de todo lo sucedido en la Nueva España, desde la formación de la Armada Real de Barlovento; despacho de la flota a cargo de[l] General Don Juan Campos, y salida de ella, hasta el primer aviso del año 1642.

2) Relación de la Nueva Vizcaya, su población y gobernadores que ha tenido.

3) Historia de la Provincia de Yucatán.

4) Historia del Nuevo México. ${ }^{28}$

Sin embargo, García no incorporó ninguna otra referencia suplementaria que confirmara la existencia de dichos manuscritos. De igual forma, el autor no mencionó los archivos o bibliotecas en los que las obras podrían estar resguardadas; además, García omitió información que podría clarificar si las obras que enumeró se tratan de manuscritos originales o copias de otros documentos. Con base en las referencias y en nuestra propia revisión de fuentes, concluimos que Jesús M. García simplemente consultó el libro anteriormente mencionado de Andrés González de Barcia y transcribió la información en él contenida, incurriendo en algunas omisiones. Con base en esta información de García, nos dimos a la tarea de corroborar la existencia de los manuscritos que atribuyó a Villagutierre. Respecto de la obra Relación de todo lo sucedido en la Nueva España, desde la formación de la Armada Real de Barlovento..., la BNE resguarda un documento impreso con un título similar, pero no igual al que provee García. El título del mencionado documento es Relacion de todo lo sucedido en estas provincias de la Nueva España: desde la formación de la Armada Real de Barlovento, despacho de flota, y sucesso della, hasta la salida deste primer aviso del año de 1642. Esta obra impresa aparece bajo la clasificación VE/1460/12 de la BNE. ${ }^{29}$ Sin embargo, además de la diferencia con el título atribuido a Villagutierre, esta obra no contiene ninguna información que permita confirmar a Villagutierre Sotomayor como su autor. ${ }^{30}$

${ }^{28}$ Villagutierre Sotomayor (1985, p. 7).

${ }^{29}$ Relacion de todo lo sucedido en estas provincias de la Nueva España: desde la formación de la Armada Real de Barlovento, despacho de flota, y sucesso della, hasta la salida deste primer aviso del año de 1642, en http://bdh-rd.bne.es/viewer.vm?id=0000085258\&page=1 (consultado el 8 de enero de 2017).

${ }^{30}$ Agustín Agüeros de la Portilla, menciona la aparición de una "hoja volante" impresa con el título "Relacion de todo lo sucedido en estas provincias de la Nueva España, desde la formación de la Armada Real de Barlovento, despacho de la flota, y sucesso della, hasta la salida deste primer aviso del año de 1642”. Esta publicación cuenta con 4 páginas, impresas en la Ciudad de México en 1647, aunque no incluye la casa de impresión. Véase Agüeros de la Portilla (1909-1915, p. 379). Sobre una segunda referencia, véase Wilkinson y Ulla Lorenzo (2005, p. 2023). Este libro incluye la referencia como sigue: "57 000 Relaciones. Relacion de 
En el tomo segundo de la obra titulada Epitome de la bibliotheca oriental, y occidental, náutica, y geográfica, originalmente publicada por el cronista Antonio de León Pinelo en 1629, Mateo Pablo Díaz de Lavandero y Martín, marqués de Torre Nueva, incluyó nuevo material en una edición ampliada y revisada de 1737. El tomo segundo, bajo el "Título V. Historias del Nuevo México", incluye una breve mención de la Historia de Nuevo México y de la Relacion de la Nueva Vizcaya: "Lic[enciado] Don Juan de Villagutierre, Historia del Nuevo México, M.S.O. fol. está en la librería de D[on] Geronimo Pardo. Relación de la Nueva Vizcaia i su población i Governadores que ha tenido M.S. fol. en la Libreria de Barcia”. ${ }^{31}$

Acerca de la Historia de la Provincia de Yucatán no hemos encontrado ninguna referencia acerca de la existencia de un manuscrito u obra publicada con ese nombre, a menos que consideremos que García equivocó el título de la Historia de la conquista del Itza reduccion, y progressos de la de el Lacandon... y lo haya abreviado erróneamente como Historia de Yucatán... Además García señaló que Villagutierre escribió en 1698 la Historia de la conquista, perdida y restaurazion... y que de ella se hicieron dos ediciones; la primera en 1929 y la segunda en $1953 .{ }^{32} \mathrm{Al}$ respecto debemos decir de nuevo que García no brindó suficiente información y omitió mencionar quiénes hicieron dichas ediciones. Es así que creemos que García equivocó su análisis.

Historia de la conquista, perdida y restaurazion de el Reyno y Provinzias de la Nueba México en la América Septentrional: antecedentes historiográficos

La Historia de la conquista, perdida y restaurazion... nunca ha sido editada en su totalidad y en estudios secundarios únicamente existen mínimas referencias. La primera de estas menciones aparece en 1929, cuando el geógrafo Juan Dantín Cereceda publicó su libro Exploradores y conquistadores de India: relatos geográficos; en ella el autor dedicó cinco hojas al trabajo del relator bajo el subtítulo de: "Juan de Villagutierre Sotomayor. Costumbres de los

todo lo sucedido en estas provincias de la Nueva España desde la formación de la armada real de Barlovento, despacho de flota, y suceso della, hasta la salida deste primer aviso del año de 1642. [México, s. n., 1642]. No. 2 M21, M55, M62, M143, N23. CCPB000354900-3, Medina, México, p. 211, 564. Palau 258265".

31 Torre Nueva (1737, p. 610).

${ }^{32}$ Villagutierre Sotomayor (1985, p. 7). 
indios de Nuevo Méjico". ${ }^{33}$ En ese mismo año Otto Maas publicó Misiones del Nuevo México, ${ }^{34}$ en el cual incluye un índice completo del contenido del manuscrito de Villagutierre acerca de la conquista de Nuevo México.

Como parte de la serie Manuscritos y estudios hispano-americanos, en 1953 Alfred Charles Herrera publicó algunas secciones del manuscrito Historia de la conquista, perdida y restaurazion... ${ }^{35}$ En esta obra, Herrera incluyó del libro primero de Villagutierre los capítulos del 11 al 22; los libros segundo y tercero completos; cada sección acompañada de una introducción o prólogo. Además Herrera presentó un amplio trabajo introductorio que abarca un proemio, o introducción, una sección de geografía histórica, así como de historia, y la correspondiente bibliografía. ${ }^{36}$

En 1999 Maribel Lárraga presentó su tesis doctoral La mística de la feminidad en la obra de Juan Villagutierre Sotomayor: Historia de la conquista, perdida y restauración del reyno y provincia de la Nueva México en la América septentrional (1698). ${ }^{37}$ Éste es hasta el momento el único estudio que ofrece un análisis del segundo y tercer libro de la obra, así como información acerca de la vida del relator. En específico Lárraga dedicó este estudio al análisis literario del papel de las mujeres, españolas e indígenas, en la obra de Villagutierre. Asimismo la autora hizo un análisis comparativo entre el contenido de la obra del relator con la de Gaspar Pérez de Villagrá, Historia de la Nueva México. ${ }^{38}$

Uno de los estudios secundarios más reciente es el de Manuel M. Martín Rodríguez, titulado "Primeros datos de una Edición de la Historia de la conquista, perdida y restaurazion del reino de la Nueva México en la América Septentrional de Juan de Villagutierre y Sotomayor". ${ }^{39}$ Como el nombre lo indica, el objetivo principal del autor es la preparación de la primera edición impresa de la obra de Villagutierre. En este texto el autor expone información ya conocida acerca de la vida del relator, algunas referencias bibliográficas y documentales así como cuestiones del estado actual de su investigación. Cabe señalar que en su análisis historiográfico del manuscrito de la historia de Nuevo México de Villagutierre, Martín Rodríguez refiere a una "supuesta

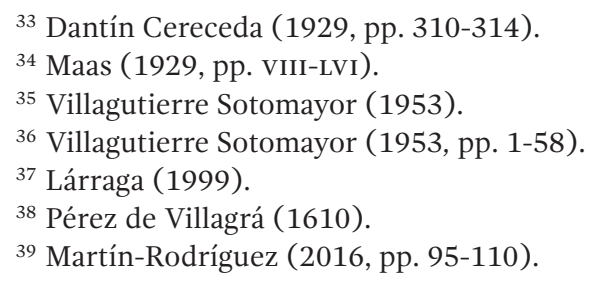


edición del manuscrito en 1929", la cual es la misma que García mencionó en su "Introducción" a la obra de los itzáes. Martín Rodríguez concluyó que esta publicación de 1929 es una "edición fantasma". ${ }^{40}$ Sin embargo, consideramos que esta conclusión es errónea y en realidad se trata de la pequeña edición de Cereceda de 1929, la cual Martín Rodríguez omitió en su estudio.

En 2017 el "Proyecto Cíbola", de la Universidad de Berkeley (Research Center for Romance Studies, Institute of International Studies, University of California, Berkeley), puso en línea el trabajo Documents Concerning the Revolt of the Indians of the Province of New Mexico. ${ }^{41}$ En la obra se presenta la transcripción de numerosas fuentes concernientes a la rebelión de los indios pueblo de 1680. En esta compilación de documentos, los autores citan la obra de Villagutierre, Historia de la conquista, perdida y restaurazion..., como fuente que refiere al líder indígena Juan Tagno, portavoz de los pueblo, y su exigencia al gobernador de Nuevo México, Antonio de Otermín (1679-1682), de liberar a los prisioneros apaches que se encontraban en Santa Fe. Cabe señalar que, a pesar de que Documents Concerning the Revolt of the Indians of the Province of New Mexico es de gran valor para la historia de la región, el trabajo no muestra una detallada revisión de la obra de Villagutierre y solamente menciona que el original se encuentra en la BNE, sin tomar en cuenta la copia que resguarda la Biblioteca del Palacio Real de Madrid.

Autoría, localización y fecha del manuscrito

Como ya se mencionó, del manuscrito titulado Historia de la conquista, perdida y restaurazion de el Reyno y Provinzias de la Nueba México en la América Septentrional existen dos copias: la primera resguardada en la BNE; mientras que la segunda se encuentra en la Biblioteca del Palacio Real de Madrid. El presente estudio se apoya en el manuscrito resguardado en la BNE dado que se encuentra accesible en línea. Este manuscrito consta de dos volúmenes de 449 y 446 folios cada uno. El nombre del autor aparece en la portada de la copia resguardada con la leyenda: "Escribió esta obra Don Juan de Villagutierre y Sotomayor."

La ficha de catalogación ubica la manufactura del manuscrito entre los años 1601 y 1700, lo cual representa una brecha muy amplia de tiempo. Sin

${ }^{40}$ Martín-Rodríguez (2016, p. 95).

${ }^{41}$ De Marco y Craddock (2017, pp. 2, 21, 25, 44). 


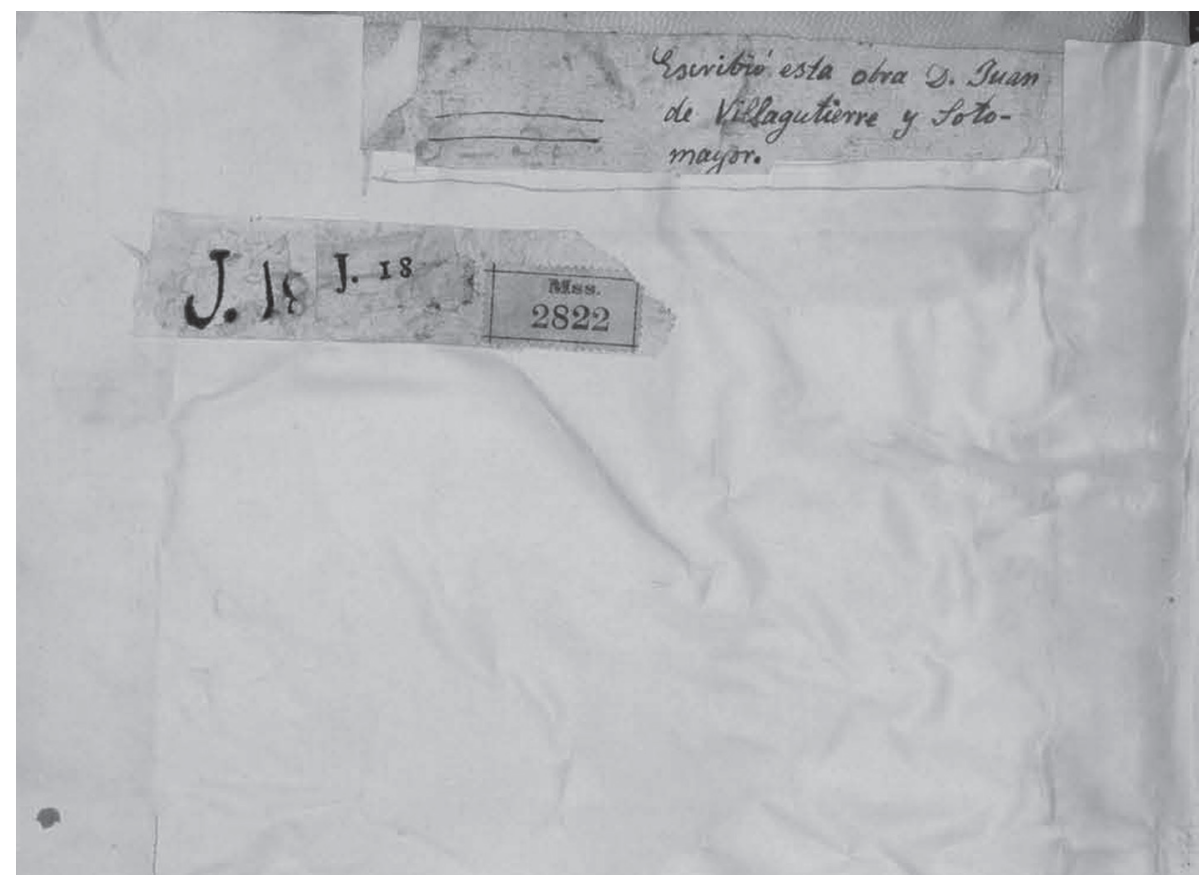

Figura 1. Contraportada del manuscrito de Villagutierre Sotomayor acerca de la historia de Nuevo México. Esta imagen evidencia la autoría de Villagutierre Sotomayor de este manuscrito. BNE

embargo, con base en la información que Villagutierre incluyó en sus obras, podemos asegurar que el autor escribió primero la Historia de la Provincia del Itza, y después se dedicó a escribir la Historia de la conquista, perdida y restaurazion... En su Historia de la conquista del Itzá, Villagutierre mencionó como último evento contemporáneo, la fecha en que terminó su obra de los itzáes, la muerte de Roque de Soberanis y Centeno, gobernador de la Provincia de Yucatán (1665-1699), quien falleció en 1699. Acerca de este dato, Villagutierre, escribió:

Estando los progresos de estas reducciones en el estado que hemos visto, dio fin el gobernador Don Roque de Soberanis a su gobierno, con su fallecimiento, entrando a sucederle (luego que murió) y tomando la profession de la Capitanía General, y gobierno de aquellas Provincias de Yucatán Don Martin de Ursúa, que hoy las gobierna, juntamente con las del Itza. ${ }^{42}$

${ }^{42}$ Villagutierre Sotomayor (1985, p. 658). 
Esta información es parcialmente correcta, ya que Ursúa en efecto ejerció como gobernador interino de Yucatán de 1695 a 1696, años en los cuales Soberanis y Centeno se encontraba en la Ciudad de México resolviendo asuntos relacionados con acusaciones en su contra. En 1696 Soberanis regresó de la capital de la Nueva España y retomó el control de la provincia hasta su muerte el 25 de septiembre de $1699 .{ }^{43}$ Entre el 25 y el 28 de septiembre de ese año, Antonio de Barbosa y Juan José de Cabero, alcaldes ordinarios de la ciudad de Mérida, ejercieron poder interino hasta que el 28 de septiembre de 1699, cuando finalmente Martín de Ursúa fue nombrado gobernador de la provincia, puesto que ocupó hasta el mes de mayo de 1703 para embarcarse a la capitanía general de las Filipinas.

En el manuscrito Historia de la conquista, perdida y restaurazion..., Villagutierre sugirió que comenzó a escribir esta obra después haber concluido la historia de la conquista del Petén Itzá:

Escribí la historia de la conquista de los itzáes, y lacandones de la mediación entre Yucatán, y Guatemala en la América Septentrional en tiempo que se estaba en lo más vigoroso del estrépito e inquietud más para sujetarlo no habiendo sido bastantes las suavidades de la palabra evangélica para reducirlos [...]. Llegué con la narración de estos prósperos hasta el límite que tenía cuando ya eran capaces de formar bastante volumen, el cual di a luz con el nombre o título de primera parte de aquellas conquistas, y dejando llevar del mismo aire con que ellas caminaban $[\ldots] .{ }^{44}$

En el mismo texto el autor también recalcó el interés que lo motivó a escribir ambas obras:

haciendo reflexión a que en la misma historia de los itzáes en el capítulo del libro tratado de diferentes sublevaciones, y crueldades que aportando ejecutaron los indios de diferentes provincias de aquella gran península septentrional entre las cuales fue la más execrable la de los del reino de la Nueva México tocándola así transitoriamente con promesa de dar a la pluma, y a la estampa e[x]profeso la conquista, pérdida y restauración de aquel reino y sus provincias. ${ }^{45}$

${ }^{43}$ Means (1917, p. 112).

${ }^{44}$ Villagutierre Sotomayor ( $\dot{1} 1704$ ?).

${ }^{45}$ Villagutierre Sotomayor (¿1704?, ff. 1-1v). 
En la Historia de la conquista, perdida y restaurazion... Villagutierre mencionó una serie de eventos que permiten sostener la hipótesis de que el relator terminó de escribir la historia de la conquista del Petén Itzá y después se dedicó a conformar la historia de la conquista de Nuevo México. En la última página de la Historia de la conquista, perdida y restaurazion... se lee:

Vinieron los papeles autenticos de las operaciones desta ultima tercera reduczion, o rreconquista a la Çiudad de Mexico, y a manos del Conde de Moctezuma que ya se allava Virrey de la Nueba España, y oi Duque de Atrisco, y Governador del Consejo de Indias, a tiempo que ya su Magestad Catholica en atençion a los espeçiales serviçios del Governador Don Diego de Bargas, de la primera, y segunda reduczion de aquellas gentes de la Nueba Mexico le había echo merced de titulo de Castilla y de prorrograzion del Gobierno, y Capitania General de aquel Reyno, y del Castellano de sus fuerzas por otros çinco años mandando se les diessen grazias, y privilegio de pazificador, del qual gozassen todos aquellos que se ubiessen enpleado, y ocupadosse en los progessos de tan gloriosas facziones, como se havían executado en aquel Reynado de la Nueba Mexico, y sus Provinzias=. ${ }^{46}$

En esta sección del texto Villagutierre establece que el conde de Moctezuma, José Sarmiento de Valladares, duque de Atrisco, permanecía como gobernador del Consejo de Indias, posición que ocupó de 1705 a 1708. De igual forma, Villagutierre mencionó en esta sección que el gobernador Diego de Vargas había concluido un periodo adicional de cinco años que el virrey directamente le había otorgado debido a los exitosos resultados en la pacificación de Nuevo México. Con base en esta información podemos afirmar que Villagutierre hizo referencia al año de 1704, fecha en la que posiblemente terminó de redactar la Historia de la conquista, perdida y restaurazion...

Contenido del manuscrito Historia de la conquista, perdida y restaurazion e índice general

Acerca del manuscrito debemos mencionar que, debido a los constantes cambios de caligrafía, ortografía, tachaduras y notas al margen, evidencia la existencia de por lo menos tres o cuatro amanuenses. Una revisión de la grafía, el estilo y la ortografía contenidos en el manuscrito revela que al

${ }^{46}$ Villagutierre Sotomayor (¿1704?, f. 447). 


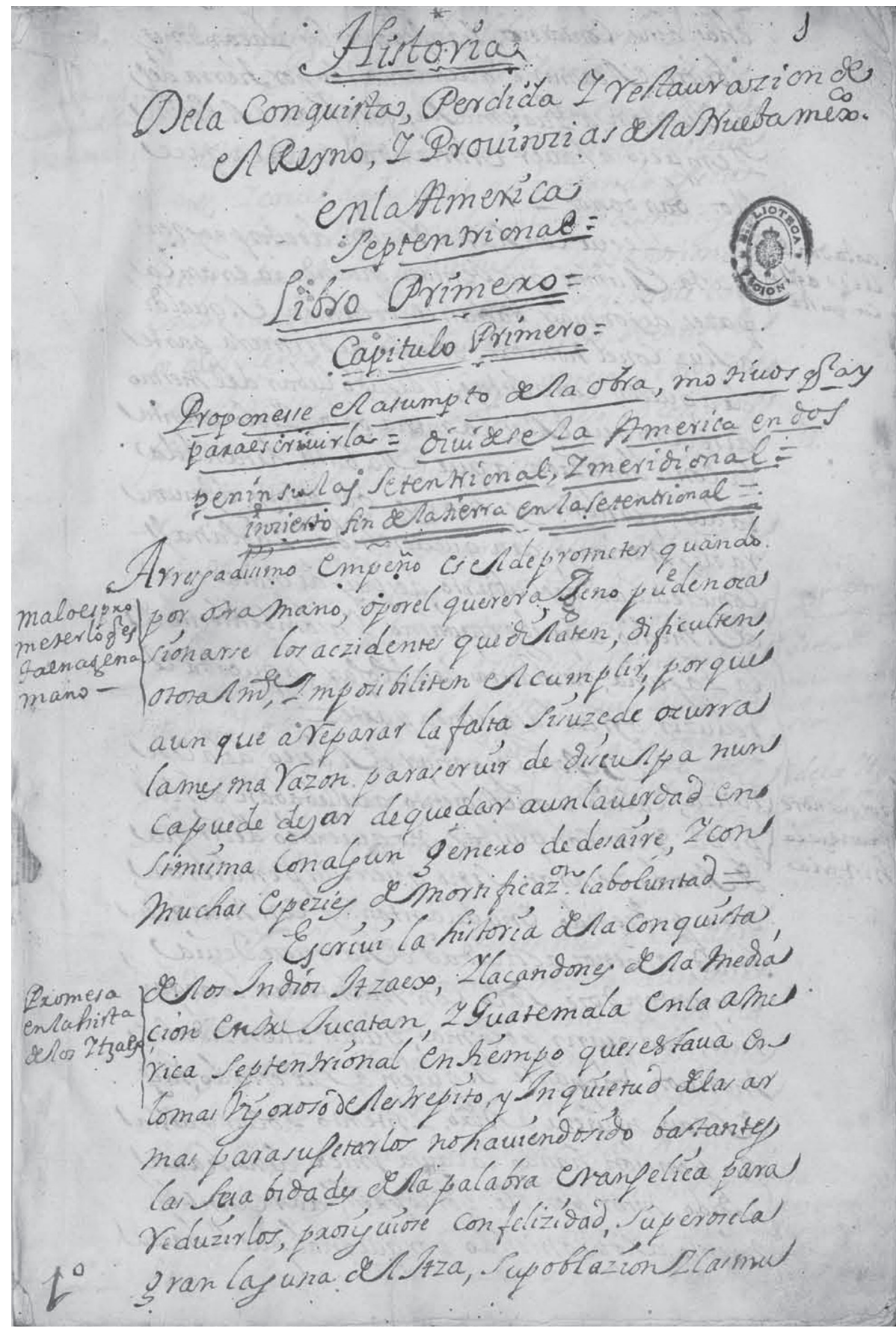

Figura 2. Portada del manuscrito acerca de la historia de Nuevo México. Manuscrito de la BNE 
menos uno de los amanuenses que participaron en la compilación de este volumen no era hispanohablante, sino probablemente hablante del idioma italiano. ${ }^{47}$ Esto no muestra ninguna excepción en la producción de manuscritos al interior del Consejo de Indias, sino una constante, ya que está bien documentado que varios amanuenses y escribanos del Consejo venían de las provincias italianas más afluentes de ese entonces, y que muchos de los escritores de Indias se ayudaban de copistas y auxiliares. ${ }^{48}$

El documento contiene diversas secciones organizadas de forma cronológica, en las cuales cada entrada corresponde a un subtítulo en particular. Así, la organización del manuscrito se divide en "libros” y éstos a su vez en capítulos. La obra contiene diez "libros" y cada uno de ellos incluye entre diecisiete y veintidós capítulos en promedio. La organización de los "libros" y sus correspondientes capítulos sigue un patrón de estricta numeración, por lo menos hasta el "libro 8", en el cual el amanuense cometió varios errores en el conteo de los capítulos ya que después del capítulo 14, el escribano siguió con el capítulo 8, y al capítulo 11 le sigue el capítulo 16. Aun considerando estos errores, en términos matemáticos diremos que el manuscrito incluye diez "libros" y un total de 198 capítulos.

Acerca del contenido del manuscrito, la Historia de la conquista, perdida y restaurazion... comienza con información geográfica de las Américas y de sus primeros pobladores de ambos hemisferios. Consecuente con el imaginario europeo de la época, el autor hizo particular mención a la existencia de pigmeos en el Perú y a los gigantes del hemisferio norte. En esta sección Villagutierre constantemente aludió a las obras e interpretaciones hechas por diversos cartógrafos, exploradores o cronistas del Viejo Mundo que coadyuvaron a la creación de un quimérico continente:

Y la península septentrional en cuyo interior se encierra el no menos rico, poderoso imperio mexicano con tantos, o más reinos provincias, y gobernaciones que en la meridional continuándose hasta la Estotilandia, o por mejor decir hasta donde la majestad de Dios es servida pues por aquel rumbo del norte hasta el día de hoy nadie ha sabido cuánto corre lo firme de la tierra haviéndose surcado los mares costa a costa leguas sin número, hasta ponerse debajo de la altura de más de sesenta y siete grados del polo ártico sin acabar de dar término a la tierra, ni hallar paso para romper Alcatayo, a las islas Molucas y a la India oriental, obligando a retroceder lo intensísimo, insufrible del frío, intolerable destemplanza del continuo hielo

${ }^{47}$ Apuntes... (1873, p. 128).

${ }^{48}$ Rivero Rodríguez (2004, pp. 19-41). 
que llega a cuajar las aguas del mar y abraza como fuego las velas de las naos la asperura, especie de granizo menudo que cae. ${ }^{49}$

El autor continuó el contenido del manuscrito con la historia del poblamiento de la capital de la Nueva España, el cual explicó como el resultado de las migraciones chichimecas, y la forma en que éstos fundaron el "imperio mexicano". A partir de este punto, el autor describió la exploración que Pánfilo de Narváez llevó a cabo en la Florida para después ocuparse específicamente del naufragio que sufrió Álvar Núñez Cabeza de Vaca y sus acompañantes, y la manera en que llegaron a Culiacán, actual estado mexicano de Sinaloa. A partir de aquí, el contenido del manuscrito describe en detalle las experiencias de Cabeza de Vaca y sus compañeros en los territorios del norte, desde los encuentros que éstos tuvieron con los pobladores originarios de la región hasta su interés y cuitas en la búsqueda de la ciudad de Cíbola. ${ }^{50}$

La historia de Cabeza de Vaca y su grupo de náufragos termina para dar comienzo a las exploraciones hechas por Francisco Vázquez de Coronado en los territorios del norte. ${ }^{51}$ Es a partir de este punto que el autor centró sus descripciones en las diversas "entradas", exploraciones, y territorios que los españoles "descubrieron" al norte de las Américas. Culiacán, Sonora, Isla de Cedros, Zacatecas, Durango y Nuevo México son algunos de los lugares que los españoles exploraron y sometieron en nombre del monarca español. Es a partir de esta sección y hasta el final de la obra que el autor se interesó por incluir los nombres de los personajes más relevantes para entender la historia del territorio de Nuevo México durante la colonización española. Nombres de exploradores, políticos y líderes españoles como los de Francisco de Ulloa, Gaspar Pérez de Villagrá, el virrey Antonio de Mendoza, así como los conquistadores Alonso Pacheco y Juan de Oñate, son constantemente mencionados en el resto del manuscrito.

Asimismo, la obra incluye los nombres de algunos líderes teguas, xemes, tanos, pecuríes y zuñis, como los de Pedro Naranjo, Antonio Malacate, Luis

${ }^{49}$ Villagutierre Sotomayor ( $\dot{i} 1704$ ?, ff. 3v-4).

${ }^{50}$ Núñez Cabeza de Vaca (1555).

${ }^{51}$ Carta de su Majestad de Vázquez Coronado en que hace relación del descubrimiento de la provincia de Tigüex, 20 de octubre de 1541, y Jaramillo, J., Relación hecha por el capitán Juan Jaramillo, de la jornada que había hecho a la Tierra Nueva en Nueva España y al descubrimiento de Cíbola, yendo por general Francisco Vázquez Coronado, 1537, ambos documentos en Pacheco et al. (1865, pp. 563, 304-329). 
Tupatu, Antonio Bolsas, entre otros. Igualmente, este apartado incluye valiosa información acerca de las poblaciones indígenas de la región y las alianzas que entre estos grupos existieron, lo que hace de esta sección del manuscrito una rica fuente de geografía etnopolítica de la región previa a la invasión española e incluso posterior a la imposición del orden colonial. Los últimos libros explican la forma en que la diplomacia y alianzas que los españoles colonos lograron establecer con los indígenas de la región, especialmente con los xemes, contribuyeron a la supresión de diversas rebeliones indígenas contra los hispanos. Es así que el manuscrito incluye información acerca del fin de las refriegas indígenas que desestabilizaban la región, así como la muerte del líder pecurí Antonio Jupatu. En esta sección del manuscrito Villagutierre describió la forma en que sucedieron las reducciones de los últimos rebeldes indígenas, para finalmente explicar el fenómeno de lo que los españoles llamaron "la reconquista" de Nuevo México. El manuscrito concluye mencionando la instauración de Diego de Vargas como gobernador de Nuevo México por mandato directo del virrey de la Nueva España. Con este último evento el autor da por concluida su obra y atestigua el fin del periodo de conquista, reconquista y pacificación de la provincia de Nuevo México a manos de los hispanos.

Para tener una mejor apreciación del contenido del manuscrito de Villagutierre, incluimos el siguiente cuadro:

CUAdro 1

CONTENido DEL MANUSCRito Historia DE LA CONQUisTa, PERDIDA Y RESTAURAZION DE EL REYNO Y PROVINZIAS DE LA NUEBA MÉXICO EN LA AMÉRICA SEPTENTRIONAL

\begin{tabular}{cc}
\hline Número de "libros" & Resumen acerca del contenido \\
de la obra
\end{tabular}

Libro 1, capítulos 1, 2, 3, 4, Historia acerca de los primeros pobladores de las Américas: la existencia de gigantes en el norte y pigmeos en el sur.

Libro 1, capítulos 4-8 Migraciones de toltecas y chichimecas y el comienzo de los nobles linajes en la capital de la Nueva España e historia de los mismos.

Libro 1, capítulos 8-11 Expedición de Pánfilo de Narváez en la Florida, las exploraciones de Cabeza de Vaca y los tres sobrevivientes del naufragio y su paso por Culiacán, y los territorios de Nuevo México. 
CuAdro 1. Continuación

\begin{tabular}{cc}
\hline Número de "libros" & Resumen acerca del contenido \\
y capítulos correspondientes & de la obra
\end{tabular}

Libro 1, capítulo 12-22

Exploraciones de Francisco Vázquez de Coronado en

Libro 2, capítulo 1-10

Culiacán y Nuño de Guzmán, entrada del padre Marcos de Niza, toma de posesión de las ciudades de Cíbola, Acus, Tonteac y Marata.

Exploraciones de Francisco de Ulloa en la isla de Cedros y su subsecuente naufragio.

Expediciones, entradas y batallas en los territorios de Nuevo México. Exploraciones de Fernando de Alarcón, Francisco Ibarra, en Zacatecas; Alonso Pacheco, Durango; Antonio Espejo. Amenaza de los ingleses en los territorios del norte de la Nueva España.

Libro 2, capítulo 11-19 Expediciones hacia el norte y a lo poblado de Nuevo Libro 3, capítulos 1-19 México, captura de "indios intérpretes", resistencia de los indígenas de la región; fundación de la villa de Santa Fe, y envío de los primeros colonos.

Libro 4, capítulos 1-2 Descripción del reino de Nuevo México, gobierno de las gentes de ahí, recursos naturales y tradiciones de los indígenas, costumbres de justicia.

Libro 4, capítulos 3-21 Rebelión de indígenas en Santa Fe, temores en la Libros 5-8 Nueva Vizcaya y Sonora.

Libros 9 y 10

Pacificación en Santo Domingo Pueblo, Tegua, Cochiti. Descubrimiento de plata en Santa Fe. Pacificación a manos de Diego de Vargas. Alzamiento en San Cristóbal, San Ildefonso, Xemes, Cochiti. Muerte de caciques indígenas. Llegada de víveres desde la Ciudad de México. Pacificación contra los Xemes y auxiliares.

Libro 10, capítulo 17 Reducción de los rebeldes y establecimiento de Diego de Vargas como gobernador de Nuevo México.

Fuentes que el autor consultó

Similar a su obra acerca de la conquista del Petén Itzá, Villagutierre Sotomayor no incluyó una lista de referencias u obras que consultó para crear el contenido de la Historia de la conquista, perdida y restaurazion... Este manuscrito también carece de notas o fuentes citadas, lo que dificulta identificar el material que el autor revisó. Es probable que, análogamente a su obra 
previa, el Consejo de Indias haya puesto a su disposición una importante serie de documentos referentes a este tema que hasta ese momento se encontraban en España. Sin embargo, en el manuscrito resguardado en el Archivo del Palacio de Madrid, en la foja 635v, el amanuense incluyó una lista de referencias, las cuales se leen a continuación:

En el tomo 3 de Juan Batista Ramusio están las relaciones siguientes que ¿miran? a esta historia:

La de Alvar Núñez Cabeza de Vaca.

La de Nuño de Guzmán, de las empresas hasta Xalisco.

La de Francisco de Ulloa con la armada de Hernando Cortés.

Don Carlos de Francisco Coronado a las 7 ciudades de Cíbola.

Carta de Don Andrés Mendoza, virrey de la Nueva España al Emperador sobre el descubrimiento de esta tierra.

Fray Marcos de Niza, relación del viaje hecho a Cíbola, reino de las 7 ciudades, con otra de Francisco Vázquez Coronado.

Relación de la Navegación de Don Fernando Alarcón a descubrir [el] mar las 7 ciudades. $^{52}$

Siguiendo el patrón que anteriormente había seguido en su Historia de la conquista de Lacandón... Villagutierre parafraseó o copió literalmente fragmentos enteros de estos mencionados documentos sin dar crédito alguno. Por lo tanto, es evidente el carácter parcial con el que Villagutierre también compuso su historia de la conquista de Nuevo México sin dar crédito a los autores originales de las relaciones que consultó y con un sesgo que favorece a los líderes conquistadores.

\section{Contexto histórico del manuscrito}

Dentro de este contexto, diremos que tanto el contenido como la fecha en que Villagutierre Sotomayor probablemente concluyó la escritura de Historia de la conquista, perdida y restaurazion... ofrecen invaluable información acerca del contexto histórico de la obra. Considerando el marco temporal mencionado, existe una serie de eventos que debieron influir no sólo en el

${ }^{52}$ Villagutierre y Sotomayor (¿1704?, f. 635v). Cabe señalar que, después de ser restaurado, este material no está disponible para consulta física en las salas de la Biblioteca del Palacio, sólo en versión digitalizada. 
contenido del manuscrito, sino también en el objetivo que la obra tenía para el reino. Resulta indispensable señalar que a mediados del siglo XVII el imperio español enfrentaba una de las crisis más intensas para controlar, administrar y mantener las vastas colonias en las Américas bajo el control de la casa de los Austria. ${ }^{53}$ Dentro de este contexto la obra de Villagutierre adopta un sentido significativo, pues describe los esfuerzos, no sólo de españoles, sino de religiosos e indígenas aliados, por mantener bajo su control los diversos territorios que los españoles ya habían clamado para la Corona.

Es así que consideramos que por lo menos cuatro grandes eventos o situaciones fueron los que Villagutierre valoró para dar forma a su Historia de la conquista, perdida y restaurazion... La primera de ellas es la serie de exploraciones que tanto los franceses como los ingleses estaban llevando a cabo en regiones cercanas a Nuevo México; la conocida como rebelión de Popé o la rebelión de los indios de 1680, la revuelta de la Ciudad de México en 1692, y la guerra de Sucesión Española de 1701 a 1714. El conjunto de estos sucesos, así como sus resultados, probablemente haya sido una de las otras motivaciones que el relator Villagutierre Sotomayor tuvo para escribir su Historia de la conquista, perdida y restaurazion...

Exploraciones francesas e inglesas en el norte de Nuevo México durante el siglo XVII

Una de las principales amenazas para que el imperio español controlara sus fronteras fueron las expediciones francesas llevadas a cabo en el sureste de los actuales Estados Unidos. Gracias a las expediciones por la llamada "ruta de las pieles”, para mediados del siglo XVIII los franceses ya habían logrado el control de algunos puntos estratégicos de los polos norteños de la Luisiana, dentro de los límites de los actuales estados de Montana y Wyoming. ${ }^{54}$ Después de la primera década del siglo XVIII, estos territorios sirvieron como puntos desde los cuales los franceses consolidaron alianzas importantes con sociedades indígenas del Misisipi, especialmente con la nación natchitoche, lo cual les permitió seguir el caudal del actual río Arkansas hasta los actuales territorios de Colorado. ${ }^{55}$

${ }^{53}$ Suárez y Gallego (1986, t. viII, pp. 343-393).

${ }^{54}$ Neill (1884, pp. 163-196).

55 Vidal (2006, p. 125). 
Por si fuera poco, los ingleses también se aproximaban al territorio de la Florida, en especial hacia la región donde actualmente se localiza el estado de Georgia, donde la rebelión de los indígenas yamasi, en la que era llamada la provincia de Guale, en 1597 expulsó a los religiosos y a las autoridades españolas por un periodo de casi un año. ${ }^{56}$ Villagutierre Sotomayor mencionó la amenaza de los avances ingleses en América en el segundo libro del capítulo cuarto intitulado "Quería la reyna de Inglaterra ocupar la Nueva México. De qué modo se supo en España. Órdenes del rey para que se conquistase. Entran los capitanes Castaño y Bonilla sin orden a quitarse la jornada con don Juan de Oñate". ${ }^{77}$ Cabe mencionar que a pesar de los avances colonizadores que los ingleses realizaban en tierras norteamericanas, estos logros nunca representaron una amenaza real a la labor expansionista española. Por el contrario, consideramos que esta mención incluida en la obra de Villagutierre obedece a una retórica que buscaba heroizar la labor colonizadora de los territorios de Norteamérica. Siguiendo esta lógica narrativa, Villagutierre argumentó en este capítulo que gracias a los reportes que hizo fray Diego Márquez directamente al rey Felipe en el año de 1588, este último decidió comenzar la colonización formal de Nuevo México en el año de 1589.

La rebelión de Popé o la revuelta de los indios, 1680-1694

El avance colonizador de los españoles se vio afectado por una serie de rebeliones indígenas que tuvieron lugar en los territorios de la recién formada Provincia de la Nueva México. Villagutierre no dudó en mencionar estos acontecimientos, así como los líderes y poblaciones que pusieron resistencia a la invasión española. Dentro de todas estas rebeliones, la que logró expulsar a los españoles fue la rebelión de los indios pueblo en $1680 .{ }^{58}$

El relativo y corto éxito de esta rebelión se debió a que los pueblo conservaron y fortalecieron su identidad cultural durante la primera ocupación posterior a la primera incursión de Oñate en $1598 .{ }^{59}$ Del mismo modo, la resistencia de los pueblo no fue un fenómeno aislado, sino que otros grupos, como los zuni y los apaches, aprovecharon el aparente "abandono" de los

\footnotetext{
56 Johnson (1923, p. 44-53).

57 Villagutierre Sotomayor (i1704?, ff. 106r-110v).

${ }^{58}$ Rubio Mañé (2005, pp. 151-226).

${ }^{59}$ Knaut (1964).
} 
territorios cercanos a Santa Fe, la gran distancia que existía entre éstos y los grandes asentamientos españoles del sureste, para desestabilizar la labor colonizadora hispana. ${ }^{60}$

Eventualmente, la división entre los indígenas y las expediciones militares españolas para reconquistar la provincia permitieron que para el mes de mayo de 1695, después de violentos enfrentamientos entre españoles e indígenas de la región, los colonizadores se reinstalaran en Santa Fe. Con el nombramiento de don Diego de Vargas como nuevo gobernador de la provincia de Nuevo México, la Corona española consolidó el proceso de reconquista de la provincia.

\section{La revuelta en la Ciudad de México de 1692}

Mientras esto acontecía en las provincias del septentrión, en el año de 1692 la Ciudad de México sufrió una de las carestías de maíz y trigo más alarmantes en su historia. ${ }^{61}$ Aunque existían otros productos que evitaron la hambruna generalizada de la población en la capital del virreinato de la Nueva España, la forma corrupta en que las autoridades responsables distribuyeron los alimentos para deliberadamente inflar los precios de los granos fue inaceptable. ${ }^{62}$ Este escenario detonó la revuelta pues la corrupción fue tan evidente que las autoridades responsables fueron denunciadas incluso por el mismo clero. ${ }^{63}$ La carestía de dichos granos afectó mayormente a las clases bajas de la ciudad lo que provocó que las tensiones entre las castas que componían la sociedad novohispana se polarizaran. ${ }^{64}$

Tanto la revuelta como las consecuencias legales que siguieron al evento demuestran el temor de los españoles a perder su hegemonía y control en el territorio colonizado. Este desasosiego no parecía del todo infundado si se considera que la población española en la capital iba en descenso, mientras la flexibilidad social entre miembros de distintas castas era una constante realidad. ${ }^{65}$

\footnotetext{
${ }^{60}$ Rubio Mañé (2005, pp. 197-198).

${ }^{61}$ Sigüenza y Góngora (1932, pp. 57-61).

${ }^{62}$ Muriel (1998, p. 109).

${ }^{63}$ Feijoo (1965, p. 657).

${ }^{64}$ Feijoo (1965, pp. 670-672).

${ }^{65}$ Feijoo (1965, pp. 672-674).
} 
La guerra de Sucesión española de 1701

Por otra parte, no debe quedar de lado que la producción de la Historia de la conquista, perdida y restaurazion... se llevó a cabo durante uno de los cambios más significativos en la historia de la Corona en la península ibérica: el final del poderío de los Habsburgo y el comienzo de la era de los Borbones. A finales del siglo Xviı la Corona española estuvo en manos de Carlos II (1661-1700), proclamado rey de España en 1665 después de la muerte de su padre Felipe IV, quien, de cierta forma "legó a su sucesor un erario público vacío, una moneda desacreditada y una multitud de nuevos impuestos". ${ }^{66}$ Cuando Carlos II subió al trono, la situación empeoró aún más. Ante la corta edad del rey, y luego por su falta de fuerza física y mental, Carlos II se vio obligado a delegar el poder a su madre, y después a favoritos y ministros. El reinado del último de los Austria fue más una monarquía aristocrática conformada por una nobleza que evadía la carga fiscal y se negaba a entregar donativos, ${ }^{67}$ que una monarquía encarnada por el poder del rey.

El desajuste al que se enfrentaba todo el reino se vio reflejado en la disposición que desde España se hacía para las colonias en el Nuevo Mundo. Mientras Carlos II tuvo la Corona, fueron nombrados 72 consejeros para el Consejo de Indias, de los cuales solamente 10 fungieron por más de diez años. Además, se nombraron consejeros supernumerarios con el único objetivo de incrementar salarios. Por si esto no fuera poco, el acceso a todo tipo de cargo se facilitó sobremanera permitiendo que éstos se vendieran al mejor postor. ${ }^{68}$

El último de los Austria menores murió en 1700 y un año más tarde estalló la guerra de Sucesión que se extendió hasta 1714. El nombramiento de un Borbón ocasionó serios problemas separatistas; la Corona de Castilla, las Indias y los territorios de Ultramar reconocieron como rey a Felipe V, pero la de Aragón, que incluía además a Cataluña y Valencia, reconoció a Carlos III. Después de que Felipe V ganara una serie de batallas y que Carlos de Austria heredara el Sacro Imperio Romano-Germánico bajo el nombre de Carlos VI, se firmó en 1713 el Tratado de Utrecht, con lo cual se le otorgó al Borbón el reino español, terminando con esto el periodo de inestabilidad política de la península y sus colonias.

\footnotetext{
${ }^{66}$ Lynch (2007, p. 557).

${ }^{67}$ Lynch (2007, p. 716).

${ }^{68}$ Lynch (2007, p. 757).
} 


\section{Conclusión}

El manuscrito Historia de la conquista, perdida y restaurazion... es resultado fehaciente de la confluencia de los acontecimientos anteriormente señalados, los cuales marcaron un periodo en el que las zonas fronterizas del norte del virreinato corrían el riesgo de ser retomadas por sus habitantes originales. Villagutierre Sotomayor manifestó en el contenido de su obra los temores que las autoridades coloniales tenían o querían resaltar argumentando la existencia de rebeliones indígenas que tomaban lugar durante esa época, sospechas que se reafirmaban con la revuelta en la Ciudad de México. En este caso, la expedición de bandos y regulaciones segregacionistas y de opresión hacia los habitantes indígenas o de otros grupos buscaba demostrar el poderío que los colonizadores españoles mantenían sobre la capital. Si bien estas medidas iban encaminadas a controlar a la población, dichas regulaciones se insertaban dentro de un objetivo más global, que era mostrar a las potencias europeas, como Francia e Inglaterra, la supremacía militar y política que la Corona española aún mantenía sobre uno de los territorios más importantes de las Américas: la Ciudad de México.

Del mismo modo, la obra de Villagutierre Sotomayor refleja el temor del imperio español a perder colonias en las Américas en un momento de transición crítico dada la sucesión real y las revueltas al interior de sus colonias americanas. En este sentido, Villagutierre dejó testimonio de las "grandes conquistas" en las Américas como obra directa del liderazgo de los Habsburgo. Posiblemente, este hecho pueda revelar en una investigación posterior, los motivos particulares de la o las personas que solicitaron a Villagutierre la escritura de la historia de la conquista de Nuevo México.

Los nombres de religiosos que exploraron los territorios de lo que hoy es Nuevo México, así como las órdenes a las cuales pertenecían, ocuparon poco a Villagutierre, quien en contraposición señaló y nombró a las autoridades civiles involucradas en el descubrimiento y la pacificación de Nuevo México, colocándolas en un plano principal. Así, Villagutierre dejó testimonio de la grandeza del imperio español durante el reinado de los Habsburgo, y al mismo tiempo sumó su obra a los pilares de la historia oficial de la Corona española en su periodo de esplendor, desde una perspectiva del Imperio, representado por el rey y las autoridades civiles.

La obra de Juan de Villagutierre es en este sentido punto clave para analizar la formación de una tradición historiográfica burocrática construida desde el imperio español para comprender los territorios del reino. Por un 
lado, la Historia de la conquista, perdida y restaurazion... nos ofrece valiosa información acerca del largo proceso de conquista de la frontera norte del virreinato de la Nueva España; y por otro, de la importancia de la producción de historias oficiales de las Indias que permitieran al imperio crear un discurso de estabilidad política y militar en los lejanos territorios de América.

Asimismo, esta obra es una rica fuente de análisis que sin duda ofrece nuevas líneas de investigación acerca de la provincia de Nuevo México y zonas circunvecinas. Si bien sería pretencioso argumentar que la obra de Villagutierre puede llenar los vacíos acerca de la historia colonial de dicho territorio, es posible considerar que un futuro análisis multidisciplinario de dicho manuscrito pueda ofrecer nuevas perspectivas para revisar la transformación histórica de la frontera norte del virreinato de la Nueva España.

Después de presentar el contenido y el contexto histórico del manuscrito de Villagutierre, quedan ciertas preguntas al aire referentes a la parcialidad, la valía y los motivos que la obra muestra a los historiadores actuales. En este sentido, es importante señalar que esta obra, similar a la de Gaspar Pérez de Villagrá y otros cronistas como Pedro Mártir de Anglería, o del mismo Francisco López de Gómara, quienes nunca estuvieron en tierras americanas, condensa una importante cantidad de fuentes de primer orden que refieren a la historia, la conquista y la vida de las poblaciones indígenas del actual territorio de Nuevo México. Consecuentemente, esta obra es una referencia obligada para el historiador actual, quien puede encontrar en el manuscrito información específica acerca de cronistas, religiosos o exploradores como Álvar Núñez Cabeza de Vaca, fray Juan de Torquemada, Juan de Oñate, Hernando de Soto, y otros más.

Las razones por las cuales creemos que el manuscrito de Villagutierre ha quedado rezagado de las actuales investigaciones son varias. La principal es que la Historia de la conquista, perdida y restaurazion... nunca ha sido publicada, posiblemente porque el autor la concluyó durante los últimos años de los Habsburgo y el comienzo del poderío de los Borbones, por lo que publicar una obra que ensalzara los logros expansionistas de los Habsburgo en las Américas carecía de importancia para los nuevos Borbones, que luchaban por la sucesión del poder. La obra de Villagutierre y su difusión pudo ser determinada por este cambio de administración en la Corona española, y no por carencia de rigor historiográfico, pues ya existía precedente acerca de su parcialidad al escribir la historia de la conquista del Itzá. Así, después de casi dos siglos, la única versión publicada hasta ahora de la obra de Villagutierre es la edición no completa de Charles 
Herrera de 1953, la cual ha dejado de publicarse, lo que dificulta el acceso y la consulta al contenido del manuscrito.

Es así que este trabajo intenta ofrecer un panorama general del legado de Villagutierre con la finalidad de atraer el manuscrito a la esfera académica y que se convierta en una fuente accesible para los interesados en el estudio de la provincia de Nuevo México.

Concluimos que la Historia de la conquista, perdida y restaurazion... puede ayudar a replantearnos la posición político-geográfica entre México y los territorios fronterizos de la Norteamérica colonial más allá de las fronteras artificiales actuales. De igual forma, consideramos que este manuscrito contribuye a la incorporación de información, el "rescate" de documentos, el enriquecimiento de los saberes acerca de la historia colonial de la provincia de Nuevo México y, sobre todo, la historia de sus pueblos, a quienes se les impuso vivir en la frontera.

\section{BiBLIOGRAFÍA}

Agüeros de la Portilla, A. (1909-1915). El periodismo en México. Capítulo iII. Siglo xviII. Anales del Museo Nacional de Arqueología, Historia y Etnología, 14, 377-393.

Alamán, L. (1853). Diccionario universal de historia y de geografía. Tomo i. México: Tipografía de Rafael.

Apuntes para la historia eclesiástica del Perú: hasta el gobierno del VII arzobispo (1873). Lima: Tipografía de La Sociedad.

Bermúdez Aznar, A. (2008). El oficio de relator del Consejo de Indias (siglos XVIXVII). En Puente Brunke, J. de la, y Guevara Gil, J. A. (eds.), Derecho, instituciones y procesos históricos I. Lima: Pontificia Universidad Católica de Perú.

CÁrdenas y CANo, G. (1829). Ensayo cronológico para la Historia general de la Florida. Tomo viII. Madrid: Imprenta de los hijos de doña Catalina Piñuela. (1723). Ensayo cronológico para la Historia general de la Florida. Madrid: Oficina Real/Nicolás Rodríguez Franco.

Cuesta Domingo, M. (2007). Los cronistas oficiales de Indias. De López de Velasco a Céspedes del Castillo. Revista Complutense de Historia de América, 33, 115-150.

DANTÍN CERECEDA, J. (1929). Exploradores y conquistadores de Indias: relatos geográficos. Colección de documentos para servir a la historia del Nuevo México, 15381778. Madrid: Instituto-Escuela, Junta para Ampliación de Estudios. 
De Marco, B., y Craddock, J. R. (2017). Documents from the Early Days of the Pueblo Revolt of 1680. University of California, Berkeley: Research Center for Romance Studies. En https://escholarship.org/uc/item/4v34d0nw (consultada el 8 de enero de 2019).

Dougnac Rodríguez, A. (1994). Manual de historia del derecho indiano. México: Universidad Nacional Autónoma de México, Instituto de Investigaciones Jurídicas.

Feijoo, R. (1965). El tumulto de 1692. Historia Mexicana, 14-4, 656-679.

Fernández GARCíA, M. (1995). Parroquia madrileña de San Sebastián: algunos personajes de su archivo. Madrid: Caparrós Editores.

Greusslich, S. (2012). Text, Autor und Wissen in der "historiografía indiana" der Neuzeit: Die Décadas von Antonio de Herrera y Tordesillas. Berlín: De Gruyter.

Johnson, J. G. (1923). The Yamassee Revolt of 1597 and the Destruction of the Georgia Missions. Georgia Historical Quarterly, 7-1, 44-53.

Jones, G. D. (1998). The Conquest of the Last Maya Kingdom. Stanford: Stanford University Press.

Knaut, A. L. (1964). The Pueblo Revolt of 1680: Conquest and Resistance in SeventeenthCentury New Mexico. Norman: University of Oklahoma Press.

LÁRrAgA, M. (1999). La mística de la feminidad en la obra de Juan Villagutierre Sotomayor: Historia de la conquista, pérdida y restauración del reyno y provincias de la Nueva México en la América septentrional. Tesis de doctorado. Universidad de Nuevo México.

López de Azcona, J. M., González Casasnovas, I., Ruiz de Castañeda, E. (1992). Minería iberoamericana. Biografías mineras, 1492-1892. Madrid: Instituto Tecnológico Geominero de España/Consejo Superior de Colegios de Ingenieros de Minas de España/Sociedad Estatal V Centenario.

LynCH, J. (2007). Los Austrias 1516-1700. Barcelona: Crítica.

MaAs, O. (1929). Misiones del Nuevo México. Madrid: Imprenta Hijos de Tomás Minuesa de los Ríos.

Martín-Rodríguez, M. M. (2016). Primeros datos para una edición de la Historia de la conquista, pérdida y restauración del reino de la Nueva México en la América Septentrional de Juan de Villagutierre Sotomayor. En M. Pérez Martínez (coord.), Libros desde el Paraíso. Ediciones de textos indianos, Volumen I. Madrid: Iberoamericana/Vervuet.

Means, P. A. (1917). History of the Spanish Conquest of Yucatan and of the Itzas. Cambridge: The Peabody Museum.

Meza, R. (2009). Visión de la frontera norte de la Nueva España por Nicolás de Lafora (1766-1768). Presente y Pasado. Revista de Historia, 27, 11-30.

Muriel, J. (1998). Una nueva versión del motín del 8 de junio de 1692. Estudios de Historia Novohispana, 18, 107-115. 
Neill, E. D. (1884). Chapter V. Discovery along the Great Lakes. En French Exploration and Settlements in North America, and Those of the Portuguese, Dutch, and Swedes, 1500-1700. (Narrative and Critical History of America). Vol. 4. Boston/ New York: Houghton, Mifflin and Company.

Núñez Caveza de VACA, Á. (1906). Relación de los naufragios y comentarios de Álvar Núñez Cabeza de Vaca. Tomo I. Madrid: Librería General de Victoriano Suárez. (1555). Naufragios. Valladolid: Francisco Fernández, 1555.

Pacheco, J. F. et al. (ed.) (1865). Colección de documentos inéditos relativos al descubrimiento, conquista y colonización de las posesiones españolas en América y Oceanía. Volumen III. Madrid: Imprenta de M. Bernaldo de Quirós.

Pérez de Villagrá, G. (1610). Historia de la Nueva México. Alcalá: Luis Martínez Grande.

Recopilación de leyes de los reinos de las Indias mandadas imprimir y publicar por la Magestad Católica don Carlos II (1841). Madrid: Boix.

Relacion de todo lo sucedido en estas provincias de la Nueva España: desde la formación de la Armada Real de Barlovento, despacho de flota, y sucesso della, hasta la salida deste primer aviso del año de 1642, en http://bdh-rd.bne.es/ viewer.vm?id=0000085258\&page=1 (consultado el 8 de enero de 2017).

Rivero Rodríguez, M. (2004). Italia en la monarquía hispánica. Studia Historica, Historia Moderna, 26, 19-41.

Rubio Mañé, J. I. (2005). El virreinato. Expansión y defensa, 2a. edición. México: Fondo de Cultura Económica.

SCHÄfER, E. (2003). El Consejo Real y Supremo de las Indias. Historia y organización del Consejo y de la Casa de la Contratación de Indias (vol. 1). Castilla/León: Consejería de Educación y Cultura.

Sigüenza y Góngora, C. de (1932). Alboroto y motín de la ciudad de México del 8 de junio de 1692. Edición de I. A. Leonard. México: Museo Nacional de Arqueología, Historia y Etnografía.

Soler, J. (1529). Repertorio de todas las leyes de Castilla. Toledo: Gaspar de Ávila.

Stiffoni, G. (1984). Historiografía y política en los historiadores de Indias de la primera mitad del siglo xviı. Nueva Revista de Filología Hispánica, 33-1, 133156.

SuÁREz, L., y Gallego, J. A. (1986). La crisis de la hegemonía española, siglo XVII. Tomo VIII. Madrid: Ediciones Rialp.

Torre Nueva, marqués de (1737). Epitome de la bibliotheca oriental, y occidental, nautica, y geografica de don Antonio de León Pinelo; añadido, y enmendado nuevamente, en que se contienen los escritores de las Indias. Madrid: Francisco Martínez Abad.

VIDAL, C. (2006). Les pays des Illinois, six villages français au cœur de L'Amérique du Nord, 1699-1765. En Wien, T., et al. (ed.), De Québec à l'Amérique française: 
histoire et mémoire: textes choisis du deuxième Colloque de la Commission franco-québécoise sur les lieux de mémoire communs. Québec: Les Presses de l'Université Laval.

Villagutierre Sotomayor, J. de (1985). Historia de la conquista del Itzá. Ed. de J. M. García Añoveros. Madrid: Historia 16.

(1953). Historia de la Nueva México. Recop. de A. Ch. Herrera. Madrid: Manuscritos y Estudios Hispano-Americanos.

(¿1704?). Historia de la conquista, pérdida y restaurazión de el Reyno y provinzias de la Nueba México en la América Septentrional. Manuscrito en versión digital. Biblioteca Nacional de España, Madrid, f. 1-1v. En http://bdh-rd.bne. es/viewer.vm?id=0000039898\&page $=1$.

Wilkinson, A. S., y Ulla Lorenzo, A. (ed.) (2005). Iberian Books, Volumes II \& III/ Libros Ibéricos Volúmenes II \& III. Leiden: Brill.

\section{SOBRE LAS AUTORAS}

Teri Erandeni Arias Ortiz es doctora en Etnología y América Antigua por la Rheinische Friedrich-Wilhelms-Universität Bonn, Alemania. De 2013 a 2015 realizó una estancia posdoctoral con beca Conacyt en el Posgrado de Estudios Mesoamericanos, donde también obtuvo el título de maestría. Labora en Arbeitskreis Stadtgeschichte e.V./Gedenk- und Dokumentationsstätte KZ Drütte, Alemania; sus líneas de investigación son la historia colonial del área maya y el nacionalsocialismo alemán. Su más reciente publicación es "Los documentos de la nobleza indígena maya chontal: escritura y legitimación en la Nueva España”.

Argelia Segovia Liga es doctora en Historia por la Universidad de Leiden, Holanda. Sus líneas de investigación son temas relacionados con el estudio de la intelectualidad indígena, en especial entre los nahuas del siglo XIX, el periodo del Segundo Imperio mexicano, los discursos de descolonización indígena y el estudio de las fronteras del territorio novohispano. Actualmente colabora en el proyecto digital "Auto de fe". Asimismo es docente en la Missouri State University. Su más reciente publicación se titula “ ‘Our Divine Right to Land': Nahua People and their Struggle for the Preservation of their Communal Lands against Privatization after Mexican Independence, 1821-1847". 
